\title{
REFLECTION
}

\section{Being Uninsured Is Bad for Your Health: Can Medical Homes Play a Role in Treating the Uninsurance Ailment?}

\author{
Jennifer E. DeVoe, MD, DPbil \\ Department of Family Medicine, Oregon \\ Health \& Science University, Portland, \\ Oregon
}

\begin{abstract}
In the United States, stable health insurance coverage is associated with improved health outcomes. A lack of insurance is associated with premature death from preventable causes. Although primary care clinicians are often in a position to see firsthand the impact that being uninsured has on patients, most ambulatory care clinics are not actively involved in helping patients obtain health insurance, retain their coverage, or make important health insurance coverage decisions. The magnitude and complexity of the US "uninsurance" problem, as well as recent federal initiatives to expand coverage options, inspire important questions: Can medical homes play a more active role in helping patients find and keep insurance coverage? How can basic tenets from the chronic care model be operationalized to build systems to treat the uninsurance ailment? Creating effective processes and tools within the medical home to keep a patient insured may be as important to improving population health as helping a patient maintain a normal blood pressure. Similar system-level interventions could be used to support both endeavors.
\end{abstract}

Ann Fam Med 2013;473-476. doi:10.1370/afm.1541

W hile attending on the inpatient service, I admitted a 52-year-old man with a bowel obstruction due to stage IV colon cancer. Resident physicians on the team had different hypotheses for why he came to the emergency department with advanced disease. One physician concluded it was because he had not received colon cancer screening. Another believed he had no access to primary care, and that the emergency department was his only option for care. Others were interested in his risk factors: Did he have a family history? Was he eating a high-fat diet? We obtained his prior medical records to figure out why his cancer was not diagnosed or treated sooner and to assess his risk factors for the disease. As it turns out, he had access to primary care, had a positive guaiac fecal occult blood test, and was scheduled for a colonoscopy 6 months before this admission. Unfortunately, because of its cost he did not get the colonoscopy. His biggest risk factor for this delayed diagnosis: being uninsured.

\section{IMPORTANCE OF HEALTH INSURANCE}

In the United States, health insurance coverage is associated with better access to services and improved health outcomes. ${ }^{1-4}$ Patients unable to obtain or maintain health insurance coverage report higher rates of unmet need than those with stable coverage. ${ }^{5-9}$ Compared with insured patients, uninsured patients are at higher risk for dying prematurely from preventable causes. ${ }^{10-12}$ Although primary care clinicians are often in a position to see how lack of insurance negatively affects health, most ambulatory care clinics do not have systems in place to help patients obtain health insurance, retain their coverage, or make important health insurance coverage decisions. His- 
torically, health care financing has been separate from the delivery of health care services. Decisions about health insurance uptake and maintenance of coverage are made by employers, individuals, and/or family members. Federal and state governments also play a role in organizing and providing coverage to the elderly, disabled, poor, and other vulnerable populations.

The growing number of uninsured patients in the United States and the negative consequences of being uninsured motivated the passage of the 2009 Patient Protection and Affordable Care Act (PPACA) to enact reforms that would expand health insurance coverage options for the uninsured. For example, by 2014, the PPACA calls for expanding Medicaid to cover all Americans making less than $133 \%$ of the federal poverty level, creating state health insurance exchanges to allow individuals without employer-sponsored insurance the option to buy coverage directly, and implementing tax credits to help middle class families afford to buy insurance. ${ }^{13,14}$ The magnitude and complexity of the "uninsurance" problem in the United States and the recent events surrounding the passage and implementation of the PPACA led me to ponder the question: Can medical homes play a more active role in helping patients find and keep insurance coverage?

\section{THE ROLE OF A MEDICAL HOME}

If uninsured patients die sooner, and medical homes are to aid patients in providing and coordinating care that improves health and reduces preventable morbidity and mortality, then helping individual patients find and keep health insurance should be within a medical home's purview. Building upon the ethical foundation of beneficence, which outlines a moral obligation for clinicians to act for the good of patients, it could be argued that playing a central role in helping patients obtain and maintain insurance coverage is as important as helping a patient maintain a normal blood pressure or an optimal glycosylated $\left(A_{1 c}\right)$ hemoglobin level. ${ }^{15-18}(\mathrm{Or}$, maybe help with coverage is even more important, as it is often not possible to receive these types of medical services without insurance.) At the population level, if we consider lack of insurance to be an epidemic sweeping the country, clinicians should advocate for protecting the public's health, and health care systems should play a more active role in advocating for affordable coverage options for everyone. Although some medical organizations have a long tradition of political activity, medical professionals have not always lobbied for expanding coverage to patients. ${ }^{19,20}$ More recently, however, health care professionals have been vocal about the need for health insurance reform, and many health care systems supported the PPACA or similar legislation. ${ }^{21}$
Although the PPACA may not be implemented in its entirety (due to the US Supreme Court ruling that state participation in public insurance expansions is optional), some provisions from the PPACA will likely expand coverage options. ${ }^{22-24}$ These reforms create another unique opportunity at the individual level for clinicians and health care systems to play a more direct role in ensuring that patients find and keep health insurance coverage. For example, what can medical homes do to help patients successfully navigate health insurance exchanges to gain coverage and stay enrolled? Can medical home personnel with expertise in coordinating care and managing chronic disease also be better equipped to advise patients about important insurance options and decisions? Much of what health care systems currently do to provide health insurance support for patients is done by health care systems to provide health insurance support for patients is done once a patient gets sick and needs services. Hospitals make efforts to enroll eligible inpatients in publicly available coverage programs retroactively or as soon as they become hospitalized. Medical homes can be proactive and reach these patients before they get sick.

\section{BEING PROACTIVE: DEVELOPING SYSTEMS}

Primary care medical homes can partner with patients to reduce preventable mortality by assisting them in acquiring and maintaining health insurance coverage. This partnership can be supported by systems that are based on tenets of the chronic care model: a patient-centered, proactive, planned, and populationbased approach. ${ }^{25,26}$ If we can develop systems to know when a patient is due for his or her next hemoglobin $\mathrm{A}_{1 \mathrm{c}}$ test or antihypertensive medication refill, then we can develop systems to know when a patient is due to re-enroll in a health insurance program. As when transforming systems to provide better chronic disease care, a program to partner with patients to find and keep health insurance would require multicomponent practice changes in 4 categories: (1) increasing the expertise and skills of clinicians and other team members; (2) educating and supporting patients; ${ }_{i}(3)$ utilizing a teambased approach with more emphasis on prior planning; and (4) making better use of registry-based information systems. ${ }^{27}$ Powerful catalysts for implementing these changes are a robust electronic health record (EHR) and the maximal use of the best health information technology (HIT) tools available.

\section{Increasing Expertise and Skill}

How much do those prescribing care and services understand about cost sharing, formularies, covered services, maximums, carve outs, etc...? Although likely 
not the team member with the greatest insurance expertise, it is essential that clinicians and other prescribers increase our knowledge base regarding health insurance coverage and related information to advise patients about coverage options. Even for patients with good coverage, we must be well versed in how to make choices between equally effective diagnostic tests and treatments and be able to understand the financial impact and the population health impact of choosing high-cost, low-value options (eg, individual patients will pay more in copayments, and fewer patients in the population will have access to Medicaid coverage if others are receiving services proven to have little or no value). This knowledge is also essential to most effectively partner with patients in shared decision making about their health care. Learners from many health care disciplines should be exposed to these concepts throughout their undergraduate and postgraduate years, and this expertise should be reinforced and enhanced through continuing medical education courses and opportunities. Maintenance of certification should focus on ensuring the delivery of care that is patient centered and also evidence based.

\section{Educating and Supporting Patients}

Educating and supporting patients requires a diverse team of skilled professionals assisted by the best possible electronic resources. For example, personal health records are new, effective avenues for communicating with patients about issues relevant to their health. In addition, EHRs enable team members to stay updated about preferred medications on a patient's insurance formulary. These capabilities could be extended to include details regarding other covered services, such as colonoscopies, and required copayment amounts for referral services that are in or out of a preferred network. Currently, the complexity and variability of most payers' covered services and unique policies make this a daunting task. To fully realize this patient-centered approach, insurers must move toward simplification of policies, standardization of covered benefits, and increased transparency.

\section{A Team-Based Approach With an Emphasis on Prior Planning}

In addition to providing better support to patients, improving expertise regarding health insurance coverage among multiple team members will increase the team's ability to educate each other. It is impossible for one person to remember all the details about covered benefits for multiple insurance plans; however, having several knowledgeable team members with the ability to assist patients with individual inquiries can be valuable for everyone. If a physician orders a test, another member of the team can help to suggest alternatives or query the patient about their current insurance coverage status to ensure that they have coverage for the recommended service. Health care teams can also play a role in helping patients plan care based on available coverage options. For example, if an individual has met a high annual deductible, it might be advantageous for them to have an indicated colonoscopy before the end of the year. Finally, insurers need to be collaborative team players by creating systems that make their services more accessible to patients, being more transparent regarding covered benefits, and assisting medical home staff in obtaining high-value services for patients that will improve outcomes. Health information technology resources and EHR-based tools in the medical home designed for chronic disease management and coordination of care (eg, registries) could be harnessed to support this team-based care.

\section{Making Better Use of Registry-Based Information Systems and Other HIT Tools}

Supported by HIT tools, patient registries can be created to organize patient information by payer, coverage expiration date, or other basic coverage information. In addition to supplying information about a team's panel of patients, these data could feed into multiple electronic communications. For example, if a medical home develops a registry-based information system to keep track of patients' insurance enrollment and expiration dates, it could generate automated alerts at the point-of-care and reminders sent via e-mail or through a patient's personal health portal when a patient is nearing a required reenrollment date. Further research should be conducted to determine the feasibility and effectiveness of adapting these types of HIT tools to facilitate inreach and outreach to patients regarding insurance coverage.

\section{ATTENDING TO THE FIDELITY OF HEALTH INSURANCE COVERAGE}

As medical homes develop better systems for managing chronic disease and keeping patients healthy, clinicians will continue to hear from patients that a lack of insurance coverage has prevented them from taking essential medications, getting preventative screenings, and completing early diagnostic tests. Thus, it seems that helping a patient find and keep health insurance is a role that should be played by his or her medical home. Gains in population health from this approach would be analogous to those achieved by ensuring the delivery of evidence-based care to all patients (ie, optimizing the fidelity of health care delivery). ${ }^{28,29}$ In fact, partnering with patients to improve the fidelity of our population's health insurance coverage, that is, ensur- 
ing that all patients have the best and most continuous coverage available to them under existing and newly expanded programs, may be as (or more) important than ensuring that all patients have optimal blood pressure control, diabetes control, or timely cancer screenings. By adopting uninsurance and underinsurance as a chronic illness and applying tenets and tools of the chronic care model to treat it, medical homes have the opportunity to improve population health and make a positive difference in the lives of patients.

To read or post commentaries in response to this article, see it online at http://www.annfammed.org/content/11/5/473.

Key words: insurance, health; medical home; primary health care; access to health care; healthcare disparities; public health

Submitted October 18, 2012; submitted, revised, February 14, 2013; accepted March 15, 2013.

Funding support: Dr DeVoe was partially supported by Agency for Healthcare Research and Quality (AHRQ) grant number R01 HS018569 and Patient Centered Outcomes Research Institute (PCORI) Cycle I (2012) Contract, Health Systems.

\section{References}

1. Hadley J. Insurance coverage, medical care use, and short-term health changes following an unintentional injury or the onset of a chronic condition. JAMA. 2007;297(10):1073-1084.

2. Hadley J. Sicker and poorer-the consequences of being uninsured: a review of the research on the relationship between health insurance, medical care use, health, work, and income. Med Care Res Rev. 2003;60(2)(Suppl):3S-75S, discussion 76S-112S.

3. Gross CP, Andersen MS, Krumholz HM, McAvay GJ, Proctor D, Tinetti ME. Relation between Medicare screening reimbursement and stage at diagnosis for older patients with colon cancer. JAMA. 2006;296(23):2815-2822.

4. Baker DW, Sudano JJ, Albert JM, Borawski EA, Dor A. Lack of health insurance and decline in overall health in late middle age. N Engl J Med. 2001;345(15):1106-1112.

5. Kushel MB, Vittinghoff $E$, Haas JS. Factors associated with the health care utilization of homeless persons. JAMA. 2001;285(2):200-206.

6. Asplin $\mathrm{BR}$, Rhodes $\mathrm{KV}$, Levy $\mathrm{H}$, et al. Insurance status and access to urgent ambulatory care follow-up appointments. JAMA. 2005;294 (10):1248-1254.

7. Ayanian JZ, Weissman JS, Schneider EC, Ginsburg JA, Zaslavsky AM. Unmet health needs of uninsured adults in the United States. JAMA. 2000;284(16):2061-2069.

8. Fox JB. Vital signs: health insurance coverage and health care utilization- United States, 2006-2009 and January-March 2010. JAMA. 2011;305(4):353-355.

9. Olson LM, Tang SF, Newacheck PW. Children in the United States with discontinuous health insurance coverage. N Engl J Med. 2005; 353(4):382-391.
10. Wilper AP, Woolhandler S, Lasser KE, McCormick D, Bor DH, Himmelstein DU. Health insurance and mortality in US adults. Am J Public Health. 2009;99(12):2289-2295.

11. Lave JR, Keane CR, Lin CJ, Ricci EM, Amersbach G, LaVallee CP. Impact of a children's health insurance program on newly enrolled children. JAMA. 1998;279(22):1820-1825.

12. Ayanian JZ, Kohler BA, Abe T, Epstein AM. The relation between health insurance coverage and clinical outcomes among women with breast cancer. N Engl J Med. 1993;329(5):326-331.

13. Compilation of Patient Protection and Affordable Care Act. 2010. http://docs.house.gov/energycommerce/ppacacon.pdf. Accessed Dec 16, 2011

14. The Health Care Law \& You: What's Changing When. http://www. healthcare.gov/law/timeline/index.html. Accessed Feb 2, 2012.

15. Pelligrino E, Thomasma D. For the Patient's Good: The Restoration of Beneficence In Health Care. New York, NY: Oxford University Press; 1988.

16. Rogers WA. Beneficence in general practice: an empirical investigation. J Med Ethics. 1999;25(5):388-393.

17. Beauchamp T, Childress J. Principles of Biomedical Ethics. 4th ed. New York, NY: Oxford University Press; 1994.

18. Frankena W/K. Ethics. 2nd ed. New Jersey: Prentice-Hall Inc; 1973.

19. Colombotos J. Physicians and medicare: a before-after study of the effects of legislation on attitudes. Am Sociol Rev. 1969;34(3):318-334.

20. Colombotos J. Physicians' attitudes toward Medicare. Med Care. 1968;6(4):320-331.

21. Getting the most for our health care dollars: access to care. American Medical Association, 2012. http://www.ama-assn.org/resources/ doc/health-care-costs/strategies-rising-costs. pdf.

22. Kenney G, Dubay L, Zuckerman S, Huntress M. The Urban Institute Health Policy Center. Making the Medicaid Expansion an ACA Option: How Many Low-Income Americans Could Remain Uninsured. June 29, 2012. http://www.urban.org/UploadedPDF/412606Making-the-Medicaid-Expansion-an-ACA-Option.pdf.

23. McDonough JE. The road ahead for the Affordable Care Act. $N$ Engl J Med. 2012;367(3):199-201.

24. The Henry J. Kaiser Family Foundation. Implementing the ACA's Medicaid-Related Health Reform Provisions After the Supreme Court's Decision. August 2012. http://kff.org/health-reform/ issue-brief/implementing-the-acas-medicaid-related-health-reform/.

25. Bodenheimer T, Wagner EH, Grumbach K. Improving primary care for patients with chronic illness. JAMA. 2002;288(14):1775-1779.

26. Bodenheimer T, Wagner EH, Grumbach K. Improving primary care for patients with chronic illness: the chronic care model, Part 2. JAMA. 2002;288(15):1909-1914.

27. Coleman K, Austin BT, Brach C, Wagner EH. Evidence on the chronic care model in the new millennium. Health Aff (Millwood). 2009;28(1):75-85.

28. Woolf SH, Johnson RE. The break-even point: when medical advances are less important than improving the fidelity with which they are delivered. Ann Fam Med. 2005;3(6):545-552.

29. Woolf SH, Johnson RE. Inattention to the fidelity of health care delivery is costing lives. Am J Public Health. 2007;97(10):1732-1733, author reply 1733. 